\title{
The enactive approach and disorders of the self - the case of schizophrenia
}

\author{
Miriam Kyselo ${ }^{1}$
}

Published online: 13 October 2015

C The Author(s) 2015. This article is published with open access at Springerlink.com

\begin{abstract}
The paper discusses two recent approaches to schizophrenia, a phenomenological and a neuroscientific approach, illustrating how new directions in philosophy and cognitive science can elaborate accounts of psychopathologies of the self. It is argued that the notion of the minimal and bodily self underlying these approaches is still limited since it downplays the relevance of social interactions and relations for the formation of a coherent sense of self. These approaches also illustrate that we still lack an account of how 1st and 3rd person observations can fruitfully go together in an embodied account of disorders of the self. Two concepts from enactive cognitive science are introduced, the notions of autonomy and sense-making. Based on these, a new proposal for an enactive approach to psychopathologies of the self is outlined that integrates $1 \mathrm{st}$ and $3 \mathrm{rd}$ person perspectives, while strongly emphasising the role of social interactions in the formation of self. It is shown how the enactive framework might serve as a basis for an alternative understanding of disorders of the self such as schizophrenia, as a particular form of socially constituted self-organisation.
\end{abstract}

Keywords Enactive cognition · Autonomy - Sense-making $\cdot$ Enactive self · Disorders of the self $\cdot$ Meaning of symptoms · Enactive approach to psychopathology Self-organisation · Schizophrenia

\section{Introduction}

What cognitive scientists think about the nature of cognition has implications for understanding mental disorders, i.e. when the mind goes wrong (Fuchs and Schlimme 2009; Drayson 2009; Colombetti 2013). Today, cognitive science is in the process of overcoming the traditional reductionist picture of the mind: the view that the

Miriam Kyselo

miriam.kyselo@gmail.com

1 Department of Theoretical Philosophy, VU University of Amsterdam, De Boelelaan, 1105 Amsterdam, The Netherlands 
mind resides inside the head and brain is rejected, and instead the idea is embraced that cognition is embodied (e.g. Thompson and Varela 2001; Varela et al. 1993). Embodied cognition is a vastly growing field and comprises several schools, differing with regards to what "embodiment" means to them and which aspect of embodiment they focus on (Kyselo and Di Paolo 2013). One school of embodied cognitive science - the enactive approach - assumes that there is no clear-cut ontological split between the individual and its environment, and that the embodied mind emerges through active engagement with the world (Varela et al. 1993; Thompson 2007). ${ }^{1}$ An important methodological assumption of the enactive approach is that the study of the mind requires the consideration of first-person experience and consciousness (Lutz and Thompson 2003). On this view, pathologies of the mind are no longer reduced to dysfunctions at the neurological level, but instead seen as disorders of embodiment and as dynamically emergent. Explanations of mental disorders are proposed in terms of bodily dysfunction and by considering phenomenological inquiry on bodily experience (Drayson 2009). In this vein, Gallagher, for instance, has proposed that autism has to do with disturbances of sensorimotor functioning, rather than dysfunctional abstract high level cognitive function (Gallagher 2005). In addition to the lived subjective experience of the patient, the (non-neural) body as well as the patient's environment, Colombetti has recently argued that, on the enactive view, explaining psychopathologies must also involve the emotional and affective dimension of the disorder (Colombetti 2013).

This paper continues to explore fruitful linkages between the enactive approach to cognitive science and psychopathology by way of critically contrasting it with two recent approaches to schizophrenia. The first approach is Parnas and Sass' phenomenological account of schizophrenia as a disorder of the minimal self (Parnas and Sass 2010), referring to a person's basic bodily sense of self (Zahavi 2005). The second is a neurobiological proposal by Ebisch and Gallese that explains the struggle of persons with schizophrenia to maintain a boundary between themselves and others in terms of dysfunctional multisensory integration in the patient's brain (Ebisch and Gallese 2015). The target of the following discussion is the notion of self (or subject, or person), the relation between 1 st person subjective experience and $3^{\text {rd }}$ person explanation, as well as the strategy applied for accounting for what is wrong in the case of a disorder of the self. It is argued that both approaches presuppose a too narrow concept of the self and a limiting account of psychopathology. The discussion highlights an important task for embodied cognitive science: to integrate the bodily and social dimension in a unified account of the self. Methodologically speaking, the goal of the paper is not to discard the presented accounts but to value their insights and to elaborate on them from an

\footnotetext{
${ }^{1}$ I consider the enactive approach to be part of the broader embodied approach in cognitive science. Then again, there are different schools in enactive cognition that use the label "enactive", each focusing on particular aspects of cognition. The differences between the schools have mainly to do with a variation in focus or topic or sometimes with the degree to which they are committed to a dynamical view of cognition. For example, the sensori-motor approach investigates the role of active bodily movement and skills in bringing about experiences. The radical enactivism approach focuses more on language and on the role of narratives in shaping cognition. Neurophenomenology investigates first-person experiences in relation to neurological activity. Finally, the autonomy-based approach aims not at explaining particular functions or aspects of cognition but at an integrative framework for cognition, focusing particularly on foundational research into the nature of cognitive identity (what is a cognitive system?) and cognition as a process (what is a cognitive process?).
} 
enactive vantage point. Specifically, it is assumed that basic concepts from enactive cognition, the notions of autonomy and sense-making (Di Paolo et al. 2010; Thompson 2007; Kyselo 2014) can inspire a more encompassing view on the self and a complementary perspective on 1 st person and 3rd person perspectives. They offer a suitable framework to integrate valuable insights in recent accounts of disorders of the self: the emphasises of the bodily self, subjective experience as well as of intersubjectivity.

The paper is structured as follows: first, I introduce the two recent approaches to understanding schizophrenia as a disorder of the self, Parnas and Sass' account of schizophrenia in terms of the minimal self (Parnas and Sass 2010) and Ebisch and Gallese's neurobiological account (Ebisch and Gallese 2015). I summarize their essential insights but then critically discuss possible limitations with regards to the notion of self and their view of the nature and genesis of psychopathology. ${ }^{2}$ In the second part of the paper, I introduce the notions of autonomy and sense-making, and explore more constructively how these concepts serve as the basis for three general principles for explaining disorders of the self. Finally, and coming back to the discussion of schizophrenia, these principles are applied to illustrate how an enactive perspective on disorders of the self can begin to elaborate and complement previous embodied and social approaches to schizophrenia.

\section{Schizophrenia as a disorder of the self: new approaches in embodied cognition}

There is broad consensus in current embodied cognitive science that selfhood is grounded in the living body. Generally speaking, to consider psychopathologies of the self in terms of embodied cognitive science, thus means to consider them as alterations of the embodied self, either in terms of disturbed bodily structures and/or in terms of an altered sense of bodily self (e.g. Fuchs 2005; Fuchs and Schlimme 2009; Gallagher 2005; Parnas and Sass 2010). There are also approaches that focus on patients' disturbed capacities as a social self. These approaches aim to shed light on understanding the biological mechanisms underlying disturbances of understanding others (the problem of other minds) and the capacity to distinguish between self and others (Frith 2004; Ebisch and Gallese 2015; Ford et al. 2008; Gallagher and Vargas 2015). In what follows I focus on two approaches that illustrate how an emphasis on the body and the bodily sense of self, as well as the underlying mechanism of social cognition, can help shed light on disorders of self. Both approaches focus on the case of schizophrenia.

\subsection{Schizophrenia as a disorder of the bodily self}

Parnas and Sass suggest to consider schizophrenia as a disorder of the so-called minimal self (Parnas and Sass 2010). The minimal self is a concept from phenomenology. It refers to the bodily sense of the self and our self-experience as a unified being

\footnotetext{
${ }^{2}$ I will focus on Ebisch and Gallese's proposal because of their emphasis on the social and the self-other distinction, which chimes well with embodied cognition, even though in other respects they might seem incompatible with embodied cognitive science and remain neuro-centric.
} 
(Zahavi 2005). More specifically the bodily sense of self is described as an experience of "for-me-ness" that accompanies all other experiences, rendering them "mine". This sense of self is called minimal because, so Zahavi argues, it is the most basic and constitutive requirement for the self, i.e. without a sense of mineness, there is no selfhood. The minimal (sense of) self is composed of three dimensions that together bring about a coherent sense of self: "self-presence", which refers to the mentioned sense of "for-me-ness," first-person perspectivity pertaining to the experience of having a personal viewpoint in space and time, and phenomenality, referred to as the basic consciousness underlying all other phenomenal experiences. The minimal self is an innate property of the human organism and it is also present in animals (Parnas and Sass 2010). As Zahavi argues, the minimal self is prior to the social dimension of the self. This claim is what I take issue with below.

Parnas and Sass' proposal is that the minimal self is affected in schizophrenia. They argue that the core disorder in schizophrenia is that the bodily self "loses its automaticity and transparency" (ibid., p. 231). To explain this they rely on a concept by Minkowski, the so-called trouble générateur (Minkowsk 1933/1970). As this concept is vital to Ebisch and Gallese's as well as my own alternative reflections, let me briefly explain it.

Minkowski argues that any psychopathology involves two aspects, an "ideaemotional" aspect and a structural aspect (Minkowski 1933/1970, p. 108). The ideaemotional aspect refers to the level of psychopathological processes at which symptoms are expressed and at which we can understand, through sympathy, what the patient experiences. The "structural" aspect has to do with the particular structure that is assumed to underlie the mental disorder. Minkowski calls it the trouble générateur, which can be translated as "generating disorder" (ibid., p. 103). It is the "inner structure" of the pathology, a deeper logic, or framework, based on which all symptoms can be interrelated (ibid., p. 104). The trouble générateur presumably directly determines and intervenes on the patient's personality as a whole. For that reason, according to Minkowski, we should focus on the change of the person as a whole, not on particular psychopathological processes or functions in order to understand psychopathology. It is thus natural to ask what Minkowski took the structures of normal human personality to be. According to him, normal human personality is a "mental form of life" and equates with the "living ego" that situates itself in the world, through feelings and emotions (ibid., p. 111). And a crucial aspect of this situatedness lies, according to Minkowksi, in a person's ability to "affirm the ego". In others words, the trouble générateur affects the organisation or structure underlying a person's coherent sense of self. For that reason, Minkowski urges to conduct a phenomenological analysis to understand what structures and "spatiotemporal relations" the human ego usually uses to affirm itself (ibid., p. 112).

When Parnas and Sass rely on the notion of the minimal self they therefore follow Minkowski's call for an elucidation of the ways in which the living ego affirms itself: it does so in terms of a person's lived bodily experience (Parnas and Sass 2010). The coherence of the self is brought about through the organismic human body. Parnas and Sass proposal is that the trouble générateur in schizophrenia has to do with a fundamental disturbance of the bodily coherence of self, i.e. of Zahavi's mentioned experience of "for-me-ness" underlying all experience. Schizophrenia is based on disorders within the three dimensions of the minimal self such that symptoms can be explained 
firstly with regard to their interrelation and as aspects of a general "experiential whole" (Parnas and Sass 2010, p. 240). For instance, alienation, a common symptom in schizophrenia is understood as a deviation from one's normal sense of self-presence (the first dimension of the minimal self). Another symptom, hyperreflexivity, could be associated with disorders of the third dimension of the self, i.e. phenomenality. The second explanatory advantage of their proposal arguably is that it allows us to understand the transition between symptoms and their causal linkages. Accordingly, some symptoms in schizophrenia "may be viewed as consequences, whereas others as compensatory, coping attempts" (ibid., p. 241). One example for this would be the presumed interrelation of the symptom of alienation and that of social isolation: a person's experienced bodily alienation, explained in terms of a disturbed sense of selfpresence, is seen as the cause of social isolation.

Parnas and Sass's proposal sheds light on the structure of the normal living ego in terms of the living body, which situates the person in the world. I argue that there are two issues with this proposal that invite more elaboration. However, let me first introduce a recent neuroscientific perspective on schizophrenia, which can be seen as a complement to Parnas and Sass' account.

\subsection{Schizophrenia as dysfunctional neurological disintegration}

While Parnas and Sass consider the perspective of the embodied self as lived and experienced, Ebisch and Gallese assess the neurobiological mechanism underlying the experience of the embodied self (Ebisch and Gallese 2015). They thereby focus explicitly on symptoms of the self in the intersubjective domain, that is, disturbances in the social capacities of the person such as empathy, as well as the ability to distinguish self from others. Like Parnas and Sass, Ebisch and Gallese also make a proposal for the trouble générateur in schizophrenia. In their view it should be defined in terms of neurobiological processes. ${ }^{3}$ Their argument is thereby structurally similar to that of Parnas and Sass. It relies on an account of abnormalcy in terms of the absence of normal functioning: in healthy subjects the (bodily) sense of self is based on a multisensory integration of particular brain activities in the premotor cortex. A multisensory integration is the normal prerequisite for making the distinction between self and others. Making this distinction between self and other is a social capacity of the individual, which itself correlates with differentiated responses in the posterior insular cortex. Ebisch and Gallese observe that subjects diagnosed with schizophrenia show disrupted multisensory integration in their brain, and they also show neuronal dysfunction correlating with the capacity to distinguish self-representations from other-representations. There is, they argue, "abnormal functional connectivity" between the two brain complexes, the premotor and insular cortices, and they suggest that this neuronal incapacity to integrate shifts from self to other-based bodily experience causes the severe social deficits attributed to patients with schizophrenia. For Ebisch and Gallese, the trouble générateur, the basic structure which underlies the disorder of the self in schizophrenia, is thus equal to dysfunctional or "aberrant" physiological structures

\footnotetext{
${ }^{3}$ This is actually not in accordance with Minkowski's structural approach, which rejects a causal explanation of psychopathology in terms of physiological deficiencies (Minkowski 1933/1970, p. 107).
} 
underlying the bodily sense of self and the ability for a self-other distinction (Ebisch and Gallese 2015, pp. 228-234).

Ebisch and Gallese's proposal can be seen as complementary to Parnas and Sass' account. It offers a neurobiological explanation of what constitutes disturbances of the coherent sense of self and thus parallels Parnas and Sass' first-person description of (some of) the phenomenology of schizophrenia with a third-person causal explanation of the disorder. But how are these perspectives related? In the following I argue that even though the two accounts adopt different perspectives - one is descriptive, the other causal - they share two epistemological presumptions that invite further questions: the view of the self as primarily body-based, a tendency to overlook the role of social interaction in the generation of the disorder and the presumed explanation of a disorder in terms of the absence of normalcy.

\section{Worries with current approaches to schizophrenia}

Both proposals conceive of schizophrenia as a disorder of the self. This is not obvious because researchers have only recently began focusing more explicitly on the self or person as point of departure for understanding the disorder (Kean 2009; Parnas and Sass 2003). By considering schizophrenia as a disorder of subjectivity, in its bodily and intersubjective dimension, and by focusing on the person and self who exhibits the disorder, the authors depart from a classical reductionistic picture, according to which schizophrenia is mainly associated with severe cognitive dysfunction. Parnas and Sass' account thereby on the one hand clearly makes a contribution to so-called phenomenological psychiatry (Jaspers 1968; Fuchs 2002), which considers subjective reports to be crucial elements in an explanation of the disorder's nature. Ebisch and Gallese, on the other hand, emphasize that a great part of suffering in schizophrenia stems from the fact that the person has severe problems in relating to other subjects. Their proposal reminds us that a great part of symptomatic experiences in schizophrenia concern the person's social functioning.

Both proposals also share a particular view of the nature of the self as essentially embodied, presupposing that the sense of self emerges as a property of the living organism (including the brain). The two accounts of schizophrenia are examples of a more progressive account of psychopathology, which can be summarised in terms of an emphasis on subjective experience, sociality, and embodiment. However, their approach invites two further questions that importantly already pertain to the 'normal' case: how do experience, sociality and embodiment interrelate? And what exactly is the authors' strategy for explaining psychopathology? Let me discuss the latter question first.

\subsection{Schizophrenia as the absence of the normal experience}

Parnas and Sass suggest that experiences in schizophrenic selfhood are disorders of experiences of normal selfhood and at the same time they say that the sense of self in schizophrenia is absent or opposed to the normal. While this observation might me valid, this view of psychopathology is also limited. Indeed, it falls under a strategy that one can call a "a mere change of the sign" (Merleau-Ponty 2002/1945, pp. 123-124). 
On such a view, the disorder is seen as the absence of the normal and the normal is the absence of the disorder.

One has to acknowledge that self-experience in schizophrenia deviates from what counts as 'normal' self-experience. It allows us to differentiate psychopathological states from non-psychopathological states. Phenomenology is thus clearly a useful tool to help with this task, since it provides more accurate descriptions of both the structures of psychopathological and non-psychopathological self-experience. However, the problem with this change-of-sign strategy is that the disorder is not accounted for beyond stating that there is, indeed, an absence of a proper or normal sense of self-presence. But, as Minkowski had written in objecting to Jaspers' phenomenological approach to psychiatry (Jaspers 1912/1968): an account of psychopathology must not merely collect descriptions but also reveal something about the organizational structure underlying the symptoms (Minkowski 1933/1970). The same point was made by MerleauPonty in his reflections on psychic blindness (Merleau-Ponty 2002/1945, pp. 118-150). Illness, he argues, is a "complete form of existence" and so in order to account for it we need to go beyond "noting things as present or absent". Instead one has to comprehend symptoms and understand their deeper meaning and function in relation to the person as a whole. This therefore transcends mere descriptions or assumption of material causes (ibid. pp. 132-133). Merleau-Ponty's worry applies to both Parnas and Sass' as well as Ebisch and Gallese's account.

Admittedly, Parnas and Sass' proposal entails an argument about the organizational structure of the self: it is bodily and it is experienced as a profound sense of "for-meness". But this organization does not figure in their explanation of the disorder other than that it is seen as a direct alteration of what counts as normal. This is unfortunate because it also risks downplaying the relevance of a patient's subjective experiences. At first glance this worry might seem counter-intuitive, for isn't their idea precisely that subjective reports are relevant? So in what sense does their account downplay such reports? The reason is that while initially the authors refer to the subjective perspective of the patient, i.e. of the person who has or is a disordered self in trying to understand the subject's struggle, and thus in accounting for the meaning or role of the patient's symptomatic experiences, the authors shift to another person's first-person experience. This perspective belongs to that of the average subject who embodies a habitual sense of self, a sense of self which in a given society counts as acceptable or habitual experience of selfhood. What then is missing is an understanding of meaning and value from the actual patient's viewpoint, or an empathetic stance of understanding symptoms through "putting oneself into the patient's shoes" (Jaspers 1912/1968). Parnas and Sass make sense of symptomatic experience by comparing it to the normal case, but how are the reports related to the particular patient's existence or self as a whole? ${ }^{4}$ For Parnas and Sass, experiences appear to matter as a confirmation that something is wrong. For example, understanding that an experience of alienation is part of a more complex bodily self-experience. However, why is it that the patient would feel alienated and what has alienation actually has to do with the disorder?

\footnotetext{
${ }^{4}$ This question also holds more specifically when, in their descriptions of the experiences of the person with schizophrenia, the authors do not consider a particular but "generalized" patient exhibiting symptoms recognized as invariant across different individuals.
} 
Similarly, to say that the patient is socially isolated because she is alienated does not consider what being alienated or feeling alone means for the patient herself. Such an account underestimates the deeper relation between experience and the subject's total being. It limits the trouble générateur to a descriptive stance.

This has of course to do with the concept of the minimal self underlying Parnas and Sass' approach. It is a phenomenological concept and seeks to describe experiences and the structure of experiences as they present themselves and not to explain them in terms of their scientific causes. However, as I argue below, an understanding of disorders of the self remains limited when the experiences are not related to the actual person who has them. This is different from asking for the physiological causes of an experience. We still need to explain the genesis of symptoms and how they are interrelated, i.e. in terms of what Jaspers has called "genetic understanding". Such understanding requires a perspective that transcends the descriptive level of psychological processes and of phenomenological analysis (Jaspers 1912/1968). Phenomenological descriptions in terms of the minimal self lack an account of normativity, by which I mean the sense in which experiences can matter or have value for a person's self. I take this to be the main point behind Merleau-Ponty's criticism, as well as behind Minkowski's concept of the trouble générateur. Both Minkowski's “ego" and Merleau-Ponty's "total being" refer to an underlying third that transcends both symptoms and experiences and yet also stands in relation to them. I argue below that without such a normative account linking experiences (and thus symptoms) to subjectivity in general we can neither understand experiences in psychopathology nor why and how they should play a role for the patient. ${ }^{5}$ We see in the next section that Ebisch and Gallese's proposal entails a similar problem.

\subsection{A causal and neurophysiological account of schizophrenia}

In contrast to Parnas and Sass, Ebisch and Gallese consider subjectivity in terms of its neurological basis and suggest that the social deficits and symptoms in schizophrenia are caused by dysfunctional neurological mechanisms. Ebisch and Gallese's proposal is part of a recent trend in neurophenomenology attempting to link phenomenological insight more closely to neuroscientific observations concerning the relation between the bodily dimension of self and intersubjectivity. At first glance, one might argue that they thus accommodate one of the noted limitations in Parnas and Sass' proposals, namely to provide an explanation beyond psychological processes. For example, they argue that "abnormal intensity of neural activity in sensorimotor circuits might contribute to the phenomenon that others' experience is perceived as ours" (Ebisch and Gallese 2015 , p. 225) and that the "absence of vicarious activation in certain regions of primary sensory cortex when witnessing others being touched could be coresponsible for the absence of real first-person bodily feelings during social perception" (ibid., p. 226). The authors are thus careful to emphasize that

\footnotetext{
${ }^{5}$ Note that although related, this concern should not be confused with the hard problem of consciousness, and the question of qualia, or the assumed gap in accounting for what a given experience really feels like for a person. The question of the meaning of subjective experience is not about the privacy of experience and why it has a "feel" to it at all, but rather about the role that the experience plays for the person, both with regard to and in the context of the person's making sense of her self and the world.
} 
particular brain regions are "co-responsible," but their wording suggests that the disrupted sense of self in schizophrenia is ultimately caused by neurological dysfunction. However, while their account goes beyond phenomenological considerations, Ebisch and Gallese's argument risks being tautologic (Kyselo 2015). It basically says that there are two kinds of neural correlates - on the one hand, neurological activities that correlate with a disturbed sense of self - and on the other, neurological activities that correlate with a disturbed self-other distinction. Their explanation then consists of a combination of both kinds of neural activities in that the inability to establish a boundary correlates with a dysfunction of the interrelation between the two neurological dysfunctions. However, this only explains one neurological activation pattern with another. As valid as the observation might be that a person's brain shows altered brain activity, such alteration does not account for why a person has experiences classified as symptomatic to begin with, not if the point is to say more than that any experience a person has is accompanied by some activation pattern in her brain.

Similar to Parnas and Sass, Ebisch and Gallese thus employ a "mere exchange of fore sign"-strategy, exchanging the sign with regard to the person's normal and abnormal neurophysiology. They explain one physiological cause in terms of another. As a consequence, though initially deemed essential by the authors for understanding the disorder, the argument downplays the insight that patients experience severe problems in the social dimension. One might ask what the point in considering patients' phenomenological reports of their struggle is when the subjects' reports are only taken as a confirmation of the fact that they differ from the healthy case and correlate with "abnormal" neuronal function? The valid insight of patients' reports that their disorder involves difficulties differentiating between self and others risks being jeopardised because these experience are not understood with regard to the patients' perspective and self as a whole but rather compared on the basis of an external and generalized standard of normalcy. In Parnas and Sass, the external standard is defined in terms of idealised and societal normative expectations about what a healthy sense of self must feel like, and has to do with the intuition that the body is what makes us a unified centre of being. In Ebisch and Gallese, it is defined in terms of medical and neurobiological norms about which neural activity should correlate with an individual's social abilities. But what the symptomatic experiences mean with regard to the person or self having them, or why the distinction between self and others would matter at all, remains unclear. I will come back to these issues in the subsequent section on enactive cognition. But let me now formulate a second worry with regard to the two proposals.

\subsection{Individualism downplays the role of the social}

In the previous section I clarified the perspective on psychopathology adopted by the authors. In this section I ask what epistemological background they thereby assume, especially regarding the nature of self and its relation to the body and the social. Both accounts actually entail a similar argument about their interrelation: the sense of self is grounded in a bodily experience of for-me-ness, i.e. of a coherent sense of one's own self and therewith the ability to distinguish one's own experiences from those of others. This coherence and differentiation from other people is seen as a prerequisite 
for being able to engage in relations to them. Consequently, when a patient shows disturbances of the bodily sense of self then these must lead to disturbances in the person's relations with others. The same relation holds vice versa. When a person has disturbances in her ability to relate to others, then this is due to a disturbance of the (bodily) self. This view makes two important presumptions: first, that the minimal self is a property of the body and that the body's boundaries are given through the individual physiological body, beginning and ending at the border of one's skin, and second, that our social capacities and the ability to distinguish oneself from the other are capacities of the individual person. On this view, the core of subjectivity and the human self is not social, but solely grounded in the individual body (brain). This view on the nature of the self as essentially bodily has been criticised. Indeed, it amounts to the so-called "body-social problem", the systematic problem in philosophy of cognitive science to interrelate the bodily and social dimensions in a unified perspective of the individual human self (Kyselo 2014). The view of the self as equal to the body risks an isolated view of the self and a dichotomy between the subject and its social environment, while viewing the self as essentially social risks losing the subject in the interaction process.

Indeed, as shown above, Parnas and Sass' proposal is based on the minimal self, and thus on the phenomenology of individual embodiment. The self-affective organism which grounds the minimal self is concerned with "obstacles, tools, objects of the desires" (Parnas and Sass 2010, p. 236). It is, however, explicitly not concerned with (experiences of) intersubjectivity. The constituents of a disorder of subjectivity are thus to be found solely within the brain or body of the single subject. Problems in the intersubjective domain are caused by disturbances of bodily processes of the individual but they do not matter themselves in the constitution of a coherent sense of self. This presumption seems to be the reason for why they are also not included in Parnas and Sass' account of the trouble générateur in schizophrenia. ${ }^{6}$ But if schizophrenia was a disorder of the minimal bodily self, then the analysis of the spectrum of symptoms should at the most be concerned with disturbances at the level of object perception, say, as in hallucinations. Overlooked is, however, the fact that an abundance of symptoms in schizophrenia concern a person's social capacities. ${ }^{7}$

The point of these considerations is not to argue with the usefulness of a phenomenological account of schizophrenia. However, the preoccupation with the minimal self as bodily clouds the phenomenological lens so that there is an overemphasis on the self as separate subject, while downplaying the open and relational dimension of self and self-experiences. Phenomenological psychiatry also has to understand what social symptoms in schizophrenia could mean and express with regard to the person who has them.

\footnotetext{
${ }^{6}$ Following Zahavi, Parnas and Sass acknowledge the interrelation of minimal and social narrative self (Parnas and Sass 2010, p. 230). In their proposal however they solely rely on the former. They explicitly disregard "important developments pertaining (for example) to intersubjectivity and temporality" (ibid., p. 232, my italics).

${ }^{7}$ The self qua being equated with the individual body would have to be a locus of separation from others. But then isolation should not only be a symptom of schizophrenia but should already be part and parcel of normal subjectivity.
} 
The social dimension of schizophrenia is explicitly mentioned in Ebisch and Gallese's proposal. But it suffers from a similar problem because it does not integrate this insight in their account of the trouble générateur, arguing instead that the locus of the disorder is the individual's living body. When the authors speak of the patient's "reduced capacity" (p. 228), "inability to resonate" (p. 222), and her "aberrant brain function" (p. 231), it becomes clear that the symptoms are seen as brought forth by the subject (or her brain, to be more precise) in isolation. In their account, intersubjective engagements play a role only in terms of neurological correlates of the result of social disturbances. This again reflects the mentioned solipsistic view of selfhood, leading to a view of psychopathology in which the responsibility and genesis of the disorder lies entirely within the patient. Even though schizophrenia is observed to consist in a struggle of the social ability to distinguish self from other, the fact that this struggle exists in the realm of social interactions does not figure in the explanation of schizophrenia itself.

To conclude this section, both the phenomenological and neurobiological approaches to schizophrenia presented appear to merely confirm that there exists a disorder at their respective level of explanation. Accepting either stance on schizophrenia leaves us with a misleading choice: either adopting a descriptive stance on symptoms, as is the case with Parnas and Sass's phenomenological proposal, without understanding the disorder beyond the level of (partial) experiences of self, or providing a causal explanation in terms of physiology without understanding social experiences or embodiment. Neither option relates explicitly to the question of what symptomatic experience means to the subject as a whole. Both approaches reduce the person's self as a whole to the human body, revealing a solipsism and - in Ebisch and Gallese's case - a persistent cognitivism according to which the brain is the seat of control. Both accounts can be seen as expressions of the body-social problem and are at risk of brushing over subjective experience in the interpersonal dimension of the self. This applies in two senses: through adapting a third-person evaluation of reports in schizophrenia and through promoting an important, but also only partial dimension of human self experience - being separate from other - to a conclusive fact about human nature in general. However, human nature is not solipsistic, but deeply social. We distinguish ourselves not from material objects, but from other subjects. And so we experience our self not merely as an island but also as connected to others, as caring for them and as being open to their influence. This fact has little relevance in the discussed contributions. As a consequence, and contrary to what their proposals might initially and rightfully suggest, the authors not only underestimate the role of the subject and its struggle in psychopathology, but they also underestimate the subject and human social experience in general. ${ }^{8}$

\footnotetext{
${ }^{8}$ One might object to these considerations that Parnas and Sass actually attempt to provide an explanation of symptoms in schizophrenia that not merely involves considering them as a deviation of what should be the normal case. They argue for looping effects of symptoms, suggesting for example that social isolation can be explained by linking it causally to the symptom of self-alienation. It is because the patient feels alienated that she feels "ontologically different from others, and therefore alone" (ibid., p. 233, original emphasis). Social isolation is "an outgrowth from within, from this inner sense of profound ontological solitude" (ibid.). However, this still explains one experience in terms of another, leaving not much room for an explanation (of the genesis) of these experiences that transcends individual reports.
} 


\section{Toward an enactive account of disorders of the self}

In this section I introduce the enactive approach to cognition and develop an alternative understanding of psychopathology that does not require choosing between either a descriptive stance or a causal explanation in terms of non-psychic processes, but instead integrates them. The reason why I believe that the enactive approach is a good candidate framework for shedding new light on pathologies of the self is that it currently offers the most comprehensive account of cognition. Methodologically speaking, the enactive approach begins considerations of the mind not by focussing on particular dimensions or aspects, but by understanding the general nature of the mind as a unified and living whole, and of mental processes as ways of preserving and organising this whole. Based on this core principle, the enactive approach then reassesses and seeks to integrate the various other dimensions and aspects of cognition. Note that I do take it for granted that the enactive approach offers a useful theoretical framework for understanding the mind. I do not wish to defend the approach on theoretical grounds against other possible frameworks of cognition. I assume that the basic idea of the enactive approach is worthwhile exploring and so my goal is to elaborate on it by making a constructive contribution and by linking it to a concrete, empirical case. To this end, I follow the enactive methodology by asking what insights can be derived for an understanding of psychopathology when it is based on an enactive account of the mind as a whole. Based on this, I offer steps for integrating the discussed perspectives on schizophrenia.

Whether the following suggestions are valid cannot solely be decided by theoretical inquiry. Ultimately it also depends on whether they allow to make better predictions and help integrate empirical findings. In the following constructive part, I first introduce the two core concepts of the enactive approach: autonomy and sense-making. Then I provide the first enactive account of the trouble générateur in disorders of the self.

\subsection{The enactive approach to cognition}

The enactive approach assumes, firstly, that there exists a continuity between life and mind (Thompson 2007; Di Paolo et al. 2010). This means that mental (or cognitive) systems share fundamental properties with living systems, despite qualitative and species-specific differences. These fundamental properties are that living and mental beings are identities that emerge through self-organisation. Secondly, such systems strive to maintain this identity and to generate meaning. They do this by evaluating themselves and the world with regards to the goal of self-maintenance. Thirdly, the emergence of living and mental identity generates a subjective viewpoint. What matters to a living and mental system is not determined by norms external to the living being, but depends on its self-organisation and on what it needs in order to keep it intact. Selforganisation is inherently subjective because it involves a concern with the continuation of existence. This is why the enactive approach adopts a complementary view of firstperson subjective insights and third-person organizational explanation. One cannot fully be understood without the other since the two are integrated within the goaldirected existence of the living and mental being (Hanna and Thompson 2003). Fourthly, living and mental systems are embodied. It is through their body that they maintain an identity and become acquainted with the world (Kyselo and Di Paolo 2013, 
Di Paolo and Thompson 2014). The following notions of autonomy and sense-making serve as key concepts for integrating these properties.

\subsubsection{Autonomy}

The concept of autonomy refers to the identity of the cognitive system as a selforganizing system. The notion is in principle applicable at several levels of description. It can refer to the identity of an individual system, such as a cell, or a body, but also to supra-identities of groups involving humans, be they dyads, institutions or even entire nations. But classically, and in line with the topic of this paper, enactive autonomy refers to the identity of an individual person or human being. The concept is associated with a particular methodological key idea: namely to ground any analysis of cognition in a view of the individual as a whole, instead of focussing on singular dimensions in isolation. The notion aims at a principle to help determine an individual's identity so as to distinguish it from other similar individuals - for humans it is presumably that which brings about a boundary between them as individual psycho-social beings. The promise is that such a notion then helps to interrelate and group other, more particular, properties and dimensions of human mental life and the organisation of the self.

A general and simple definition of autonomy is the following: an autonomous system is a precarious, self-organized network of processes that brings about and maintains an identity (following Maturana and Varela 1980; Thompson 2007). Precarious refers to the fact that these processes of that network are organized such that they enable and are enabled by each other, and thus together they ensure the network identity maintains its structure and does not dissolve (Di Paolo 2009). The formation of an autonomous identity is inconceivable without the environment. It provides the processes that the organisation is made of. The environment thus does not serve as context in which identities are embedded or situated in, but as active ingredient of the network as a whole. This is reflected by the strong emphasis in the enactive approach on a dynamical perspective concerning the relationship between individuals and their environment. Individuals are not ontologically distinct from their environment but identified against it in terms of their specific organization. This has been referred to as operational closure. ${ }^{9}$ Operational closure allows the individual, apart from becoming a distinguishable identity, to also shape and organize possible interactions with the world. Thus, what counts as a cognitive system's environment also depends on the particular organization of the cognitive system's identity (Von Uexküll 1958); it is what turns the world into "a place of salience, meaning, and value" for itself (Stapleton and Thompson 2009).

Because autonomy consists of processes that together generate a bounded network, the human self is seen as relational in nature. Until recently, these relations have been specified in terms of the body and sensorimotor activity (Thompson 2005). However, a new elaboration on the enactive self conceives of its constitutive processes in terms of social interactions (Kyselo 2014). According to this, the self is thus primarily seen as a

\footnotetext{
${ }^{9}$ This gives some hint at how the enactive notion of autonomy is related to that of other disciplines: it also has to do with a certain independence of a person, but in the enactive approach, autonomy refers to a basic an organizational independence bringing about the system as a biological, psychosocial or cultural identity.
} 
social structure and as co-enacted with others through interacting and relating to them. It is the emerging result of a continuous complexity reduction of a person's psychosocial engagement with the world. The basic organization of the autonomous self is assumed to combine two general types of psycho-social processes: acts of emancipation (distinction) and acts of open-ness and readiness for perturbation by others (participation). This two-fold structure of distinction and participation is expressed as a striving to be a person in one's own right, distinct and separate from the other while also being someone who is connected to others, and who can be affected and supported by them.

In contrast to the above discussed minimal self, on the enactive view, the coherent sense of self is therefore not simply given through an individual's body but rather through relating the body to others. This explains why the sense of self actually has a double nature: there is a sense of coherence through time, which involves experiencing oneself as a separate and distinct unity, but there is also a sense of connection, openness and belonging to others. A coherent sense of self is therefore not limited to the experience of for-me-ness, since that would amount to solipsism. Humans are not distinguished against other material objects, but against acting and goal-directed other subjects. So subjectivity, as a reflection of human self-organisation, must also involve a directedness towards the other. Indeed, the mentioned precariousness of autonomy suggests that both distinction and participation, and thus both the self-experience of mine-ness and of openness to the world of others, are required for the emergence of a coherent sense of self.

\subsubsection{Sense-making}

The second key concept of the enactive approach is that of sense-making. While autonomy refers to the identity of the cognitive system as an integrated whole, sensemaking denotes the relational and behavioral dimension of cognition (Thompson and Stapleton 2009). Importantly, sense-making is implied in the notion of autonomy. Qua generating an autonomous identity through organizational closure, a person produces a perspective on the world from which she can act as the centre and by which she separates herself from the rest of the world. This perspective emerges because a person evaluates and probes the environment with regard to what matters to the continuation of her own existence as a whole (Di Paolo 2009; Di Paolo et al. 2010). Here lies the basis for human subjectivity. Qua being brought forth through the social world, the self entails a fundamental existential normative bias. The autonomy-based view of the self is therefore teleological and intrinsically purpose driven (Weber and Varela 2002). At the heart of being a self lies a fundamental, intrinsic goal, to generate and maintain an identity which integrates both tendencies: towards distinction and emancipation on the one hand and participation and openness on the other. Since the self as a whole comprises two dimensions and they are opposed, the bias also involves a need for negotiating and integrating them so as to arrive at a quasi-stable equilibrium (a kind of balance between distinction and participation). Extreme deviations from a state that combines both a sense of separation and of connectedness - i.e., if the self was to rely on either of the two kinds of relations and interactions by themselves - risks nonadaptive forms of organization. ${ }^{10}$ For example, only (or too much of) distinction would

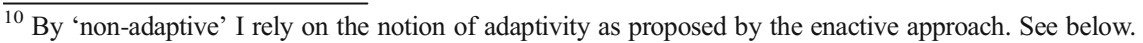


lead to isolation from others, whereas only (or too much of) participation would amount to immersion and the risk of a loss of self in the other. Human social existence is neither just isolated nor always with the other. Although, clearly, over a course of life every person will develop particular tendencies that might favour one dimension over the other.

Note that sense-making should not be understood as a mere rational, cognitive act. Autonomous systems care and they are affected by what happens to them. Enactive theorists consider this the basis for human and animal emotion (Colombetti 2013, p. 18). It is also important to understand that sense-making is not an all-or-nothing process, but involves adaptivity and flexibility (Di Paolo 2005). Adaptivity means that humans do not only react to the world, but also monitor and regulate their interactions with the world so as to improve the conditions for maintaining their identity.

What are the implications of sense-making with respect to the self? Without offering here a full-fledged enactive account of subjectivity and conscious experience, it is clear that the autonomy based view of the self puts an important emphasis on subjectivity, on the sense of self as it is experienced by the subject and also, and necessarily, on a person's experiences within the intersubjective domain. Again, not everything in the world matters; instead, environmental and individual processes acquire a particular status for the individual when they matter for the continuation of its identity. Being in the world is thus always concerned and an act of evaluation. Sense making is what an autonomous system does in order to "know" and to change how it fares in its going about in the world, or how it is situated in the temporal-spatial relation to the world. Since humans are social beings, this must mean that our sense-making behavior brings about a social perspective, both on the world and on oneself. From this perspective, subjective experiences become relevant for the system's self-organization because they are the source of meaning for the autonomous system as a social agent. Experiences generate relevant insights that relate directly to one's existence in a world of others. Without them nothing and no one could ever matter to us. They are the means by which we evaluate whether our integrity as a psycho-social subject is safe and, more concretely, whether and to which extent the two goals, of distinction and participation, are in balance. ${ }^{11}$

This is precisely why enactive theorists emphasize the complementarity between first-person and third-person explanations. To appreciate the circularity of first-person and third-person perspectives, one has to keep in mind that at the heart of cognition each mental and living being strives for the maintenance of self-organisation and for evaluating the environment with respect to this goal. The self is intrinsically goaloriented. As a consequence, subjective experiences always relate to a person's self as an

\footnotetext{
${ }^{11}$ Elaborating the enactive view on the self, the notion of adaptivity (Di Paolo 2005) might play a role here in the sense that the ability to oscillate between the two dimensions also requires flexibility. On the one hand, a self must always change with regard to a two-fold norm (distinction and participation), ensuring that neither dimension becomes too high or too low. On the other hand, since the oscillation is assumed to be enacted through being with others, adaptive change would also depend on a subject's social environment. The change also depends on the extent to which relations and interactions enable an individual to balance her needs while at the same also depend on the extent to which the oscillations and style of a person's self organization meet the expectations of a person's social environment (family, friends, professional context, etc.).
} 
organisational whole. Their meaning cannot be fully determined on the grounds of physiological facts, nor by comparison to externally derived meaning. ${ }^{12}$ The same logic applies to understand the self from a third-person perspective. In this way, physiological structures, be they neurological, sensorimotor or technology based, are seen as embedded in a person's existence as a social whole. They do not constitute this existence but rather play a role in enabling the social processes that constitute it.

From this perspective, we can better appreciate why the body is important to the self. The body is not only what establishes a boundary to others, being a place of separation through skin and flesh. It is also that which opens us up, bringing us in contact with other people and allowing us to relate and to connect to them. We saw that, according to the minimal self, the body in isolation is what matters most to our self-organization as a coherent whole. On the enactive view, it is rather how we bodily relate to others. The body is better seen as a mediator of social existence, providing an ever-developing matrix of social meaning and significance. Engagements and relations with others leave traces, bodily memories of how particular styles of being with others felt to us and were evaluated according to their contribution to the sense of self as emancipated and distinct or open and supported (Kyselo 2014). At the same time, with our body, we continuously evaluate our being in the world; through emotions, perceptions or thoughts we can appreciate how particular interactions might be relevant with regard to the organization of our self, thus guiding action and behavior that continues to organize and shape our engagements with others. ${ }^{13}$

This view on the self as an autonomous and sense-making system has a couple of important implications that are relevant for developing an autonomy based view of psychopathology. First, the maintenance of self is subject to a permanent tension that can be experienced as a struggle. A person cares for self-preservation as long as she is alive. A need for negotiation with and concern for others is inherent to this care (Kyselo 2014). Given that the two movements in this approach, distinction and participation, are opposed, this leads to a tension that a person strives to overcome without ever fully being able to. Second, based on the dynamical emergence and organization of the self, we should not assume that the self is a given or fixed thing. Not only in childhood, but also as long as a person is alive she relies on social interactions, relations, and has to negotiate her identity through being with others. Having a body is not sufficient for coherence of self. It needs to be continuously active, and that also means to be socially active. ${ }^{14}$ Third, since the self is enacted together with others, it must also not be the sole

\footnotetext{
${ }^{12}$ However, given that the self is an identity that is created with others, not every experience might be comprehensible to the subject in isolation; she might need to interact and engage with others in order to understand the significance. I argue that emotions such as shame and guilt provide a good example for this. How one evaluates a shameful emotion can depend a lot on the social context and on the reaction of others to her expression of it.

${ }^{13}$ It is beyond the scope of the paper to explore this in more detail, but obviously the two senses of bodily mediation could be seen as related. Past experiences can inform and shape future evaluations, and present experiences can alter past evaluations.

${ }^{14}$ Again, this chimes well with Merleau-Ponty's perspective on the body, according to which the nature of our behavior does not depend on our "normal" biological capacities. Our abilities are shaped through our being and acting in the world. Gail Weiss has recently offered an interesting overview of how Merleau-Ponty's insight has been used and interpreted in the context of race, feminist and disability studies. The bodies of women and disabled people, for instance, are not naturally less capable but are seen as affected and limited through the norms of a given society and thus through the limiting ways in which other people tend to relate to them (Weiss 2015).
} 
result of an individual's action, but rather emerge through joint engagement and effort. This suggests that a person has only limited control over her self maintenance and is, if partly, necessarily dependent on other subjects - other subjects have their own goals and norms and evaluate and perturbate interactions accordingly. At times these perturbations and goals might be in accord, but at others they might violate the individual's subjective goals and expectations. Finally, and following from the previous implications, the autonomy view of the self suggests that the human self is genuinely vulnerable. It is vulnerable because, qua being relational, it is always incomplete and needs to remain open, with respect to change and with respect to others.

\subsection{Three principles for an enactive account of disorders of the self}

In this section I outline how the enactive notions of autonomy and sense-making can inform an approach to psychopathology of the self and thereby address the limitations we encountered in the discussion of Parnas and Sass' and Ebisch and Gallese's approach to schizophrenia. The first basic insight to this end is that the self is a form of social self-organisation and that because it is concerned with self-preservation, it is necessarily normative and goal-directed and thus infused by subjective values. The second important idea is that self-preservation is not only relational, but a social relational process. The self is continuously brought forth through social interactions and relations. The third point is the mentioned complementarity of first-person and third-person perspectives that are joined in the existence of the social self as a whole. Based on these insights, I propose the following three principles for an autonomy-based approach to psychopathology: existence as a whole, a circular view of symptoms as expression and sense-making modality, and a view of psychopathology as an altered form of striving for quasi-equilibrium in the organization of a person's self.

\subsubsection{Disorders of the self as a form of autonomous self-organization}

The enactive approach begins considerations of the disordered human self by identifying the subject who has the disorder. The answer is: the human being as a embodied socially organised whole. A similar point was made by Merleau-Ponty, who suggested that an illness has to do with the "subject's total being" and is itself a "complete form of existence" (Merleau-Ponty 2002/1945, pp. 123-124) and Canguilhem, who argued that diseases happen to the organism in its physiological entirety (Canguilhem 1991, p. 223). This point is also reminiscent of Minkowski's quest to specify the structures of the living ego and how it affirms and situates itself in temporal-spatial relation to the world (see section 2.1).

On the enactive view of the self, the "subject's total being" or living ego is coenacted through relations and interactions with others. The subject is thus concerned with the social resources that help enact it. The main proposal is that we should assume that this continues to be the case in psychopathology. The argument for this is quite simple: self-organization is that which distinguishes living systems from non-living systems (Maturana and Varela 1980). A patient does not suddenly cease to be alive, she still exists as a human being, and therefore also as a social and sense-making existence. This means that as long as she is alive she is also and necessarily involved in selforganization, concerned with its maintenance and thus following her own subjective 
goals. More specifically, this also means that the two-fold social bias of the enactive self - to be someone in her own right while also being connected to others - and the task to negotiate and co-negotiate the tension between them, remains. One can therefore consider the disorder just as any other living human condition as a particular form of self-organization, or better even, as a form of self-other organization. Self-organization follows in principle the same logic for every human being, but there are more particular forms of self-organisation. These vary from individual to individual, depending on gender, age, social and cultural context. The enactive approach simply extends this insight to all forms of human existence. Thus, while self-organization in disorders of the self might come in altered forms but it serves essentially the same purpose: to organize the patient's psycho-social existence.

Methodologically speaking, this view would overcome the division between the third-person causal or first-person descriptive stance, neither reducing the patient to her brain (or body), as risked in Ebisch and Gallese's approach, nor to her momentary experiences, as risked in Parnas and Sass's approach. As I explore in the next sections, an enactive approach to psychopathology combines both stances in a perspective on the patient as a socially organized whole. ${ }^{15}$ It thereby considers the person in a circular and dynamical fashion through subjective experiences and evaluations of the person and, from an organizational perspective, through both intra- and extra-bodily processes, as well as the person in her relations and interactions to others.

\subsubsection{Symptomatic experience as sense-making modality}

A necessary consequence of caring for the integrity of our identity is that our behavior is never neutral but always purpose-driven and infused by values and concern. Our being in the world is always an act of sense-making and thus of evaluation, and it is a social endeavour. Just as a patient does not suddenly cease to exist as a social existence (autonomous self), she also does not suddenly cease to exist as a sense-making, experiencing subject; the patient still has a subjective viewpoint on her existence from which she monitors and regulates herself and her relations with others accordingly. This, I suggest, is the deeper reason why experiences in illness matter vitally for psychopathology research.

While it is indispensable to collect subjective data in the form of subjective reports, this data still needs to be interpreted. This is where the enactive approach would elaborate on current phenomenological approaches that mainly describe and compare reports to the "normal case". Clearly, we cannot deny that reports of suffering can be extremely incomprehensible and vague, not only to the treating doctor but also to the patient herself (Jaspers 1963). Moreover, patients often try to make sense of the meaning of their experiences by means of verbal language, risking to blur or abstract over about their concrete phenomenal nature. So in addition to describing symptoms, one must also aim to understand their meaning beyond the appearance of phenomena (Merleau-Ponty 2002/1945, p. 124, p. 132, Jaspers 1912/1968). The enactive approach accommodates this task by considering the status of symptoms from an organizational

\footnotetext{
$\overline{15}$ This is actually an elaboration of Evan Thompson's earlier proposal for bridging subjective experience and objective, material accounts, in conceiving of the mind as embodied existence (Thompson 2005).
} 
and systemic perspective, i.e., in terms of their role or status within the organization of the self as autonomous whole. This allows us not only to consider experiences of a particular subject, but it also offers a rough and ready heuristics for understanding them empathetically, from a second person perspective. Even though a person's experiences are always her own, the idea that every self involves the negotiation of a two-fold goal (distinction and participation) provides a way to account for experiences beyond the personal report of a momentary subjective experience. Basically, one understands that every experience is related to the person's concern for her ability to exist as an individual in her own right and/or to be connected and supported by others. This is what it could mean to understand experiences in alignment with the person's subjective viewpoint even when these experience are radically different from what counts as normal or familiar. ${ }^{16}$

From such a perspective, psychopathological symptoms are a form of sense-making and can be seen as strategies for achieving the goal of self-preservation and for evaluating whether or to which extent this goal can be achieved. For example, symptoms of bodily alienation could be understood as an expression of a perceived imbalance between being a person striving to exist in her own right or as someone open and connected to the realm of others. In bodily alienation the body is no longer prereflexively experienced as mediator of social existence, but as a hindrance and material object. This makes sense against the person's background as a social existence. While the body might have become a hindrance in a person's current ability to socially relate, this might also be the result of already persisting problems in relating to others. In this way, alienation can be seen as a bodily expression of an overemphasis of distinction (the dimension of self that seeks individuality, and not openness to others). The struggle with alienation might become intelligible when considered within the logic of the subject's need to counter-balance it with participation.

This perspective transcends the phenomenological level beyond descriptive purposes without however giving up on understanding a particular person's subjective experiences. A pathology has, quite literally, to do with subjective suffering and "the feeling of life gone wrong" (Canguilhem 1991, p. 137). This point could be underestimated if it was not also linked to the subject as a whole. Some symptoms can obviously be expressed in behavioral terms and thus observed and compared from an external perspective as being less adaptive, socially "inacceptable", or "abnormal" forms of being in the world. However, first of all, within the deeper logic of self-organization, the struggle itself would be seen as a form of evaluation, and thus, positively, as a form of adaptive care taking. Suffering is then never just an expression of a physiological deficiency, nor of

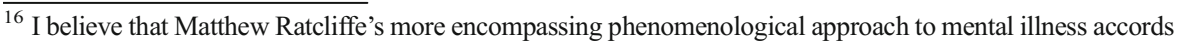
well with this project (Ratcliffe 2012). Ratcliffe emphasizes that in order to understand experiences in mental illness we should bracket our usual assumption of a "shared world" as the basis for empathising with another person. Instead, we should open up to the possibility that, in mental illness, not just the content but the very structures of experiences are altered. Ratcliffe proposes radical empathy as a phenomenological stance, by which he means being ready to be affected by the alterity of the other person's experience rather than trying to understand it by comparison to something already known (p. 483). Radical empathy is thus not limited to a first-person perspective. It means one must adopt a mode of "open" engagement with the experience of another person. I think that the enactive understanding of the self as an autonomous system that is striving to maintain its self-organization as basically open to and distinct from others provides a complement to Ratcliffe's strategy. It offers a heuristic from which empathy can arise through the insight that we are equal in existence, even though the particular ways we organize this existence might differ.
} 
abnormal behavior, but rather of the subject's particular struggle as an intentional social being in the world. Symptoms appear as testimonials of a suffering from violated subjective norms, derived from the basic two-fold goal to integrate the opposed goals of distinction and participation that make up the enactive self.

We can now formulate a second step towards an autonomy-based approach to psychopathology that reflects the structure of (normal) sense-making: symptoms can be both an expression of a person's struggle to maintain the self as socially co-enacted network, as well as of the person's subjective evaluations of that struggle, but also a person's attempt to make up for an experienced struggle in achieving the goal of selfmaintenance. By linking the understanding of symptoms to the subject's purpose driven existence as a whole, the enactive approach might provide a middle way between the descriptive and causal stance and help to illuminate symptoms that appear unintelligible at first glance. ${ }^{17}$

\subsubsection{The equilibrium hypothesis: an enactive account of the trouble générateur}

Based on two basic steps for an autonomy-based view of psychopathology: 1) adopt a perspective on the patient's existence as a whole subject, i.e. the self as socially organized existence, and 2) assume a continuity of striving for self-preservation and for sense-making, in this section, I now offer a general enactive view of the trouble générateur in psychopathologies of the self.

This view will be in accordance with Minkowski's structural approach, conceiving of psychopathology as a form of mental life that continues to be, though perhaps different at first take, a form of life. The basic hypothesis is that it is precisely because of the social structure and precariousness of human self-organization that a psychopathology can develop to begin with: we have learned that firstly, the structure of the self is inherently fragile because it is the result of the ongoing attempt to maintain a balance between emancipation from others and being connected to them. It is fragile because not only is this an open-ended process requiring continuous engagement, but also because the conditions of this engagement have to be continuously negotiated with other people. For that reason the self is also inherently and necessarily vulnerable to the influence of others. Secondly, a person, through her subjective experiences, tracks the process of self-organisation. She is thus able to perceive and identify risks and tendencies of imbalance and/or balance in self-organization. When a person experiences particular difficulties in integrating the influences on her self-organisation brought forth through her relations with others, and when she evaluates them as harmful, she can suffer and ultimately develop behaviors and further experiences that might be recognized as psychopathological. ${ }^{18}$

\footnotetext{
${ }^{17}$ Note that the notion of sense-making might admit some opaqueness to a person's experience and behavior; not everything is accessible to reflexive awareness and reasoning. This is to some extent unavoidable given that we also make sense of the world together with others. In this sense, symptoms could be expressive without a person being aware of it, thereby reflecting a limitation of the external resources or possibilities of a person's social network for joint sense-making rather than of the individual's capacities.

${ }^{18}$ Note, again, that understanding or evaluating could also be practical or prereflective embodied understanding; it need not require the person's reflective awareness. Not every evaluation might be explicit. One way of knowing implicitly, for instance, is given through embodied social emotions such as shame, guilt, pain of rejection, etc., that can drive our behavior even though we are not always aware of it.
} 
The basic idea, more concretely, is that the trouble générateur in disorders of the self is a particular version of the general struggle for self-maintenance, specified in terms of an existential oscillation between the intrinsic striving for emancipation and independence (distinction) and the striving for connection and open-ness (participation), as well as of the ongoing subjective evaluations a person is making to this end. Since the strivings are opposed to each other, and yet both are required in order for a person to become and remain a coherent self, the continuous oscillation thereby aims to bring about a state of quasi-equilibrium between distinction and participation. Subjectively speaking, a disorder of self is a state of suffering from experienced (continuous) violations of either the goal of distinction or of participation, or of what the person evaluates as an appropriate balance between them. Objectively speaking, psychopathology is a form of self-organization that exhibits particular struggles in the oscillation between and integration of the two dimensions.

The presented view entails a distributed stance regarding the constituents of self and self-organization. Self-organization, whether or not it is symptomatic, is an intersubjectively open process and involves the individual's continuous engagement with or disengagement from the social environment. This chimes well with previous work in developmental psychology. Minuchin, for instance, emphasises that the right unit of observation for understanding disorders in the family context is the dyads or triads formed between family members; in other words, between the parent and a child, or among siblings (Minuchin 1985), and not individuals in isolation. On such a view, in determining the trouble générateur, it does not suffice to look at individual physiological structures, be they neurological (as in Ebisch and Gallese's proposal) or sensorimotor-based. But neither would it suffice to consider an individual's behavior, say in terms of her social skills or abilities, such as perspective-taking, for example. Ontologically speaking, psychopathologies of the self are relational or social structures, dynamically emerging through the individual in its relations and interactions with the social world. The possibility of achieving a balance or quasi-stable sense of self through the equilibrium of distinction and participation is thus always also dependent on the social relations and interactions that a person is engaged in, on their quality, and on the degree to which they allow a negotiation and balance of the two opposed goals. It follows then that the trouble générateur does not reside or originate within the patient (in her brain or body or phenomenology), nor simply outside, in the patient's social environment, but rather within both, i.e. in the relational dynamics between them.

Let me now conclude this paper by coming back and applying these considerations to the discussion of a particular case of a disorder of self: schizophrenia.

\section{Conclusion: schizophrenia as a disorder of enactive autonomy}

In this paper I have first discussed Parnas and Sass's and Ebisch and Gallese's arguments concerning the trouble générateur in schizophrenia, and I have offered a basic perspective on disorders of the self, informed by an enactive, autonomy-based approach to the self. I have argued that both proposals have advantages: the insight of Parnas and Sass is that the trouble générateur in schizophrenia has to do with the experienced altered sense of self, and requires an account of the symptomatic experience. I argued further that Ebisch and Gallese are right to emphasize the need for an 
explanation beyond experiences, as well as the role of a functioning boundary between the person and her social environment in establishing a coherent sense of self. The problem with both approaches is, so I argued, that their account of the self and subjectivity entails a body-based individualism and that they downplay the status and role of altered self experiences and their underlying physiological structures by comparing them to the normal case.

The enactive alternative to the trouble générateur is grounded in our existential condition as social selves who strive to engage with others and need this engagement in order to generate and maintain a coherent sense of self. This approach conjoins a phenomenological account with an organizational perspective on the self as a meaning making and identity creating subject.

For the particular case of schizophrenia this suggests that schizophrenia is at the heart, like any other psychopathology of the self, deeply concerned with a subject's social existence. A person with schizophrenia still strives to create a stable sense of self, and also to negotiate the tension between being a self that is at once able to connect to others and to remain a subject in her own right. She continuously evaluates herself and her relations with others accordingly.

In line with Parnas and Sass, I suggest that the trouble générateur in schizophrenia has indeed to do with the experience of a stable sense of self. But within the enactive logic of the precarious organizational dynamics of self-construction we can elaborate on this phenomenological insight, making sense of the fact that the sense of self is not stable in schizophrenia and that subjects with the condition have extreme difficulties maintaining a boundary between self and other. The suggestion is that, in schizophrenia, the intersubjective dynamics of a person and her social environment enact a form of self-organization that is evaluated as risking or violating both of the subject's basic norms at the same time, i.e. the ability to remain a distinct subject and the ability to be connected to others.

Ebisch and Gallese are thus correct that the boundary between self/other is the key element for understanding schizophrenia. But on the enactive view we can now also explain why this should be the case. The proposal for the trouble générateur in schizophrenia is that the person's self-organization continuously risks losing its own coherence (quasi-stability) while the person also continuously strives to maintain it and thus to oscillate between distinction and participation. Whenever she tries to accommodate one of the needs, she simultaneously risks having to face the respective other, never safely experiencing a balance between them. In this way the two dimensions become increasingly more decoupled. As a consequence of this decoupling, the person must experience extreme tensions and must develop strategies for preventing an organizational break-down. More specifically, there is a sense of too much distinction and also of too much participation. The former leads to feelings of isolation, the latter to a loss of boundaries and an experienced immersion with others. Since distinction and participation are seen as inextricably linked and dependent on each other, each mode only makes full sense against the background of the respective other. Accordingly, on the one hand, the isolation in schizophrenia is an isolation from others, and the suffering from it hints at the same time at the goal of remaining connected to them (participation). On the other hand, the immersion with others amounts to a distance from oneself as emancipated 
subject, the suffering from immersion hints at the goal of being a person in one's own right (distinction). As a consequence, the person not only continuously experiences some of the most excruciating human threats, the loss of self and the isolation from others, but also a continuous extreme tension due to the lack of balance between them. A logical way of preventing organisational breakdown (the loss of compatibility of distinction and participation) would be to find ways to experience either of the two primordial modes in a safe way, for instance by diminishing the risk of failing the respective other's needs or by trying to temporally "silence" one dimension. The person might "choose" to seek stronger experiences of distinction so as to diminish tension experienced within the participatory dimension, and she might "choose" to give up more boundaries to make up for tension within the distinction dimension. Eventually, however, the person will have to accommodate the neglected need, thus returning to a vicious circle of attempted and failed alleviation of the tension between them. This failure, I suggest, lies at the heart of the boundary loss that Ebisch and Gallese rightfully assume. A coherent sense of self needs to balance the need for emancipation and for connection.

The tragedy of schizophrenia is a reflection of a basic tragedy of the human condition. When a person is unable to even remotely integrate the need of distinction and participation, she ceases experiencing coherence as a subject. She is not someone others can connect to, nor someone others perceive as independent subject. The boundaries to other people become either blurry or inexistent in her striving for participation (risk of immersion). But at the same time they remain rigid and clashing with expectations of the social environment, when she strives for distinction (risk of isolation).

The presented proposal does more than describing symptoms in terms of the absence of normalcy. We can begin to understand why a person's sense of self in schizophrenia might differ from that of other people. The self-organizing self in schizophrenia strives to observe its basic laws of self-organization, but at the same time it must continuously violate them. Even if one might struggle to empathize with the extreme or incomprehensible nature of symptomatic behaviors, this approach to the trouble générateur might help to get a grasp on the existential dimensions of the struggle that a person with schizophrenia experiences.

Methodologically speaking, the present proposal suggests that while psychopathology research needs phenomenology, sometimes it also needs to complement it with an organisational and normative perspective on subjectivity thereby allowing us to relate subjective experiences back to the self-organization of the person in question. While considering the neurological underpinning of experiences is an important aspect of such an endeavor, it remains accidental when it is not also informed by a systemic perspective from which neurological processes are seen in the light of their contribution to a larger social organization. It follows from the idea that the self is organized through social interactions and relations that the genesis and explanation of schizophrenia cannot remain limited to the individual, be it at the level of phenomenological insight or at the level of neurological processes underlying subjective experiences. The organization and maintenance of a coherent sense of self is a distributed process, involving individual and interpersonal processes. On the presented view, the trouble générateur of the disorder lies therefore also within the social environment of a patient, 
be it within the family, in the relationship with an emotionally close partner, or any other social context that is deemed to be highly relevant to a person's self. ${ }^{19}$

It goes without saying that much more needs to be said in order to specify the enactive approach to disorders of the self and to do justice to the heterogeneity of symptoms in the various disorders of the schizophrenia spectrum. The paper can be seen as an invitation for further elaboration, both in theory and in practice. A major aspect of this will be to better understand the role of the enactive body as expression and mediator of a social existence and the need to assess bodily experiences as they emerge in social relations and through ongoing interactions with others.

It is my hope that the present paper can help to set the ground for a new understanding of schizophrenia by providing a basic enactive heuristic. Within this heuristic, the disorder is approached in terms of interpersonally mediated selforganisation, and its symptoms are accounted for by assuming that there exists a normative relation between subjective experiences and the self as a coherent whole. This view presumes that all symptoms in schizophrenia are ultimately of social nature and can be considered as sense-making processes in a circular fashion: on the one hand, as very particular expressions and strategies of a person's struggle to maintain her self, and on the other hand, in terms of resources made available through the qualities of the dynamical interplay of an individual in interaction with and in relation to others.

The present proposal takes a generally positive outlook for treatment: if, as is suggested on the enactive view, the self is open and intersubjectively co-constructed, then a person with schizophrenia should remain not only open for negative perturbations, but also for positive ones. The prediction would be that any therapy approach which takes the intersubjective dynamics that a patient is involved in seriously, and that helps accommodating the patient's struggle for self-maintenance and rebalancing the dimensions of distinction and participation, should be expected to have better outcomes than that one focusing on individualistic interventions, be they on the patient's brain or her body in isolation from others.

Acknowledgments The author is grateful to Gabriel Levy, Ezequiel Di Paolo, Thomas Fuchs, René van Woudenberg and the members of the Science Beyond Science research group at the VU University of Amsterdam for their valuable comments on an earlier version of the paper. The author wishes to thank the two anonymous reviewers for their helpful comments. The author's work is supported by a grant from the "Science beyond Scientism" project at the VU University of Amsterdam.

Open Access This article is distributed under the terms of the Creative Commons Attribution 4.0 International License (http://creativecommons.org/licenses/by/4.0/), which permits unrestricted use, distribution, and reproduction in any medium, provided you give appropriate credit to the original author(s) and the source, provide a link to the Creative Commons license, and indicate if changes were made.

\footnotetext{
${ }^{19}$ In this sense, the proposed approach to schizophrenia accords well with the work of R.D. Laing, who sought to understand the struggle of the disorder by considering disturbances in the communication processes within the patient's family (see for example, Laing and Esterson 1964). Note again, however, that I do not argue that the responsibility lies with the family alone. The disorder cannot be comprehended without also considering the subject's own contribution through her continuous striving to preserve a coherent sense of self.
} 


\section{References}

Canguilhem, G. (1991). The normal and pathological. New York: Zone Books.

Colombetti, G. (2013). Psychopathology and the enactive mind. In K. W. M. Fulford, M. Davies, G. Graham, J. Z. Sadler, G. Stanghellini, R. G. T. Gipps, \& T. Thornton (Eds.), The oxford handbook of philosophy and psychiatry (pp. 1083-1102). Oxford: Oxford University Press.

Di Paolo, E. (2005). Autopoiesis, adaptivity, teleology, agency. Phenomenology and the Cognitive Sciences, 4 , $429-452$.

Di Paolo, E. (2009). Extended life. Topoi, 28, 9-21.

Di Paolo, E., Rohde, M., \& De Jaegher, H. (2010). Horizons for the enactive mind: Values, social interaction and play. In J. Stewart, O. Gapenne, \& E. A. Di Paolo (Eds.), Enaction: Towards a new paradigm for cognitive science (pp. 33-87). Cambridge: MIT Press.

Di Paolo, E. A., \& Thompson, E. (2014). The enactive approach. In L. Shapiro (Ed.), The Routledge Handbook of Embodied Cognition (pp. 68-78). Routledge Press.

Drayson, Z. (2009). Embodied cognitive science and its implications for psychopathology. Philosophy Psychiatry \& Psychology, 16(4), 329-340.

Ebisch, S. J., \& Gallese, V. (2015). A neuroscientific perspective on the nature of altered self-other relationships in schizophrenia. Journal of Consciousness Studies, 22(1-2), 220-240.

Ford, J., Roach, B., Faustman, W., \& Mathalon, D. (2008). Out-of-synch and out-of-sorts: dysfunction of motor-sensory communication in schizophrenia. Biological Psychiatry, 63(8), 736-743.

Frith, C. D. (2004). Schizophrenia and theory of mind. Psychological Medicine, 34, 385-389.

Fuchs, T. (2002). The challenge of neuroscience: psychiatry and phenomenology today. Psychopathology, 35(2002), 319-326.

Fuchs, T. (2005). Corporealized and disembodied minds: a phenomenological view of the body in melancholia and schizophrenia. Philosophical Psychiatry Psychology, 12, 95-107. doi:10.1353/ppp.2005.0040.

Fuchs, T., \& Schlimme, J. E. (2009). Embodiment and psychopathology: a phenomenological perspective. Current Opinion in Psychiatry, 22, 570-575.

Gallagher, S. (2005). How the body shapes the mind. Oxford: Clarendon.

Gallagher, S., \& Vargas, S. (2015). Social cognition and psychopathology: a critical overview. World Psychiatry, 14, 5-14.

Hanna, R., \& Thompson, E. (2003). The mind-body-body problem. Theoria et Historia Scientiarum: International Journal for Interdisciplinary Studies, 7(1), 23-42.

Jaspers, K. (1912/1968). The Phenomenological Approach in Psychopathology. British Journal of Psychiatry $114,1313-1323$.

Jaspers, K. (1963). General psychopathology. Chicago: University of Chicago Press.

Kean, C. (2009). Silencing the self: schizophrenia as a self-disturbance. Schizophrenia Bulletin, 35(6), 1034 1036.

Kyselo, M. (2014). The body social: an enactive approach to the self. Frontiers in Cognitive Science, 5, 1017. doi:10.3389/fpsyg.2014.00986.

Kyselo, M. (2015). Necessarily in-between. On the role of the social self in schizophrenia research. Comment on Ebisch and Gallese. Journal of Consciousness Studies, 22, 1-2.

Kyselo, M., \& Di Paolo, E. (2013). Locked-in syndrome: a challenge for embodied cognitive science. Phenomenology and the Cognitive Sciences. doi:10.1007/s11097-013-9344-9.

Laing, R. D., \& Esterson, A. (1964). Sanity, madness and the family. London: Penguin.

Lutz, A., \& Thompson, E. (2003). Neurophenomenology: integrating subjective experience and brain dynamics in the neuroscience of consciousness. Journal of Consciousness Studies, 10(9-10), 31-52.

Maturana, H. R., \& Varela, F. J. (1980). Autopoiesis and cognition: The realization of the living. Dordrecht: Reidel Publishing.

Merleau-Ponty (2002/1945). Phenomenology of perception. London: Routledge.

Minkowski, E. (1933/1970). The notion of a generating disorder and the structural analysis of mental disorders. In Translated by N. Metzel, Lived time: Phenomenological and psychopathological studies (pp. 220-271). Evanston: Northwestern University Press.

Minuchin, P. (1985). Families and individual development: provocations from the field of family therapy. Child Development, 56(2), 289.

Parnas, J., \& Sass, L. A. (2003). Schizophrenia, consciousness and the self. Schizophrenia Bulletin, 29(3), $427-444$.

Parnas, J., \& Sass, L. A. (2010). The spectrum of schizophrenia. In T. Fuchs, H. C. Sattel, \& P. Henningsen (Eds.), The embodied self (pp. 227-243). Stuttgart: Schattauer. 
Ratcliffe, M. (2012). Phenomenology as a form of empathy. Inquiry, 55(5), 473-495.

Thompson, E. (2005). Sensorimotor subjectivity and the enactive approach to experience. Phenomenology and the Cognitive Sciences, 4(4), 407-427.

Thompson, E. (2007). Mind in life: Biology, phenomenology, and the sciences of mind. Cambridge: Harvard University Press.

Thompson, E., \& Stapleton, M. (2009). Making sense of sense-making: reflections on enactive and extended mind theories. Topoi, 28(1), 23-30.

Thompson, E., \& Varela, F. (2001). Radical embodiment: neural dynamics and consciousness. Trends in Cognitive Sciences, 5, 418-425.

Varela, F. J., Thompson, E., \& Rosch, E. (1993). The embodied mind: Cognitive science and human experience. Cambridge: MIT Press.

Von Uexküll, J. (1958). Streifzüge durch die Umwelten von Tieren und Menschen. Bedeutungslehre. Hamburg: Rowohlt.

Weber, A., \& Varela, F. (2002). Life after Kant: natural purposes and the autopoietic foundations of biological individuality. Phenomenology and the Cognitive Sciences, 1, 97-125. doi:10.1023/A:1020368120174.

Weiss, G. (2015). The normal, the natural, and the normative: a Merleau-Pontian legacy to feminist theory, critical race theory, and disability studies. Continental Philosophy Review, 48(1), 77-93. doi:10.1007/ s11007-014-9316-y.

Zahavi, D. (2005). Subjectivity and selfhood: Investigating the first-person perspective. Cambridge: MIT Press. 